\title{
Sobre a catarse de Augusto dos Anjos
}

\section{Ubiratan Machado Pinto*}

\begin{abstract}
Resumo: com a finalidade de promover a discussão acerca da poética de Augusto dos Anjos, tem-se nesse breve estudo uma alternativa de reflexão pela qual a proposta desse ensaio tende a sugerir para possíveis leitores. Discutir sobre os anseios inerentes à humanidade, nunca abrandados quando a problemática da vida refere-se ao dilema da própria vida, refluindo para questionamentos pertinentes à mortalidade do homem. Assim, a constante tensão do indivíduo é conviver sempre com as inquietações do espírito, a catarse assustadora perante a perplexidade dessa existência, o cotidiano e com suas emoções, características que abarcam em si mesmas o traço da finitude. Eis alguns pontos fundamentais, argumentados nesse trabalho.
\end{abstract}

\begin{abstract}
In order to propose a discussion about the poetic of Augusto dos Anjos, this work aims at analyzing the inner anguishes of humanity, which are never soothed when the predicament of life is about the dilemma of life itself and, by extension, about the finitude of mankind. One's constant tension of dealing with the uneasiness of the spirit, the frightening catharsis facing the perplexity of existence, the everyday life and its emotions are characteristics which contain the trace of finitude here analyzed..
\end{abstract}

Keywords: reflection; finitude; catharsis.

Para pensarmos sobre a catarse, mediante o respaldo da interpretação aristotélica, esclarecendo-a como algo que preenche de terror ou comiseração uma circunstância vivida, antes precisamos denominar o motivo propulsor, leitmotiv dessa intensidade. Esse algo, ainda não denominado, que, nesse conciso estudo, identifiquemos como a presença arquetípica da morte, viabilizando o efeito catártico em alguns módulos literários e, por vezes, causando desconforto quando refletimos a respeito de nossa finitude. Considerada o ponto que ceifa o ar e a pulsação da vida, a morte é assimilada de acordo com experiências pessoais e nuanças culturais e religiosas. A fatalidade na poesia brasileira não raro propiciaria revés estético face à Revolução do aço e da eletricidade, o vórtice da modernidade constituindo o emaranhado econômico das relações sociais, em contrapartida à tradição parnasiana, retratando filosoficamente a crueza da transitoriedade humana através da sôfrega inspiração de Augusto

\footnotetext{
* Ubiratan Machado Pinto é estudante do curso de Letras da UFRGS.
} 
dos $A \operatorname{lnos}^{1}$, na edição de sua única obra denominada $E u$ (1912), publicada dois anos antes de falecer aos 30 anos de idade. A referida finitude não seria algo que conquistasse facilmente sentido sem antes haver esforços de curiosidade, estruturando engenhosamente o conhecimento racional para decodificar o desconhecido e, assim, fazendo submersões na própria carne da criatura, como se fosse preciso vestir um escafandro não permeável ao imergir nesse mar metafórico e desvendar a individuação interior já desenvolvida, o discernimento das informações que sobrepuja o ser humano quanto à apreensão psíquica da natureza; nesse caso na antinomia dos fenômenos captados, de princípios mutuamente inversos, fixando o discernível conforme o arranjo assimilado de idéias. E da sinonímia entre elas, processar a contrariedade, supor o lado contraditório de algum dado e, por conseguinte, termos o mapeamento das abstrações envolvidas na esfera da razão, do semanticismo das noções nessa espessa integralidade cerebral. Seguindo a linha dessa depreensão, observa-se nas células sanguíneas e naquelas preenchidas com linfa, ou seja, sangue em contraposição com a água celular na respectiva seqüência, a agregação do todo, também acolhido na antítese das idéias, e a legitimidade do paradoxismo dos sentimentos, constituindo essa universalidade promíscua (termo esse significando a mistura sem ordem de coisas ou conceitos) do intelecto. Da interioridade psíquica, a fase onírica, pela qual se "realizam" os nossos sonhos, parece simular a nossa aproximação com o ideário cósmico, com o espaço concreto e o imaterial. Em "Revelação", parte I, registremos essa dialética intrincada da existência:

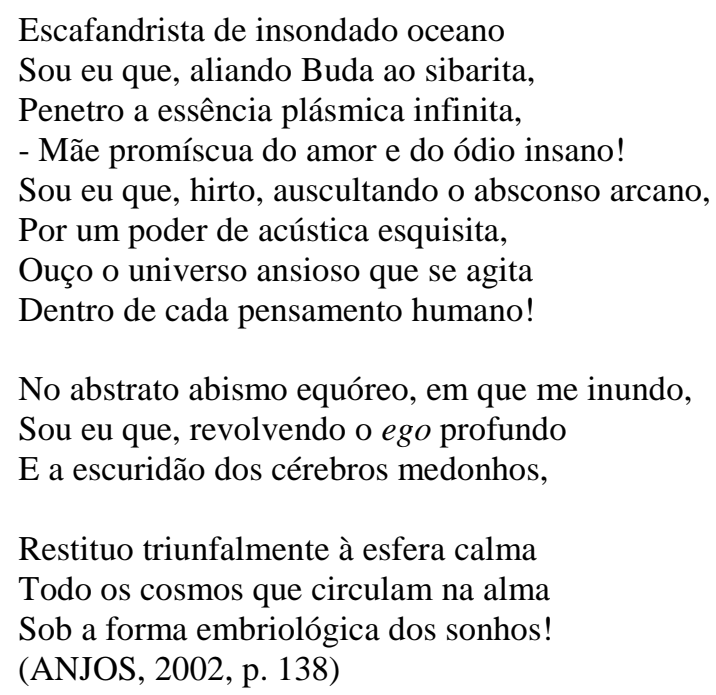

Sempre por oposição vocabular de significações, esse poema permanece a refletir na outra parte, a mesma tensão proposta na primeira. A coerência semântica, de súbito, explode intencionalmente na argumentação poética, ao relacionar, por exemplo, podridão e fragrância,

\footnotetext{
1 Augusto dos Anjos (1884-1914) nasceu na Paraíba, foi professor de ensino secundário, graduou-se como bacharel em letras e Direito; morreu prematuramente de pneumonia.
} 
matéria física e impalpável expansão do céu no horizonte, perturbação e aprofundada tranqüilidade (ataraxia, numa concepção mais espiritualizada). E tudo culmina no absoluto convertido em estado escatológico (matéria que promove o fim de si mesma) para, do absoluto mortificante, haver a renovação da vida. Vejamos a continuação dos versos:

Treva e fulguração; sânie e perfume;

Massa palpável e éter; desconforto

E ataraxia; feto vivo e aborto...

— Tudo a unidade do meu ser resume!

Sou eu que, ateando da alma o ocíduo lume,

Apreendo, em cisma abismadora absorto,

A potencialidade do que é morto

E a eficácia prolífica do estrume!

(ANJOS, 2002, p. 139)

Com narrador lírico desempenhando todas as ações envolvidas no momento presente, temos a purgação interna de seu anseio; processa-se dessa maneira a ascese, o fervor religioso pelo qual resigna o assombro da mortalidade putrescente, embora aja certa eternidade nos elementos desagregados do corpo humano. O ser torna-se a "não-substância" das substâncias. Passemos, portanto, as duas últimas estrofes da parte II desse mesmo poema:

\footnotetext{
$\mathrm{Ah}$, Sou eu que, transpondo a escarpa angusta

Dos limites orgânicos estreitos,

Dentro dos quais recalco em vão minha ânsia,

Sinto bater na putrescível crusta

Do tegumento que me cobre os peitos

Toda a imortalidade da Substância!

(ANJOS, 2002, p. 138-139)
}

Além de outras circunstâncias metafísicas questionadas pelo poeta, e não só do vocabulário cientificista empregado por ele, como também das palavras utilizadas com iniciais maiúsculas no meio do verso, a impermanência do ser, subjacente ao teor vociferante de seus poemas, constitui os preceitos do budismo: doutrina fixada na crença do desapego material e disseminada por Siddharta Gautama (o Buda) ${ }^{2}$, conforme os estágios das quatro "nobres Verdades"3. O Eu, de Augusto dos Anjos, canta assim a odisséia poética do ser vivo reduzido a intrigantes partículas atomizadas, suspensas na vastidão onidirecional de luz e

\footnotetext{
2 “buddha”, o 'Desperto'; 558 a.C. (?)- 478 ou 487 a.C. (?).

${ }^{3}$ As quatro "nobres Verdades": 1- Tudo é dor; 2- A dor nasce do desejo; 3- A dor cessa com a extinção do desejo; 4- Para extinguir o desejo deve-se seguir o caminho dos oitos passos da tradição budista; e segundo Mircea Eliade em "História das Crenças e das Idéias Religiosas" (p.110-111), a não-substancialidade do ser deriva das primeiras nobres Verdades (a dor e a origem da dor), e por lógica de causa e efeito que comanda os ciclos vitais e os renascimentos, descreve-se "o mundo das coisas e a condição humana" pela efemeridade que os caracterizam: 1- O conjunto das "aparências" ou do sensível; 2-As sensações; 3- As percepções e as noções que delas resultam; 4- As construções psíquicas, englobando atos conscientes e inconscientes; 5- Os pensamentos, "conhecimentos produzidos pelas faculdades sensoriais, e, sobretudo pelo espírito que tem sua sede no coração e organiza as experiências sensoriais.”.
} 
sombra. A atomização da unidade humana aproxima-se dessa idéia de morte orgânica, conquanto o átomo seja matéria indestrutível, e a essência dos estudos do filósofo Lucrécio ${ }^{4}$, que eliminou as superstições dos homens, habituando-os à efemeridade. O poeta exprime semelhante tipo de reflexão em "Cismas do Destino" ( $1^{\text {a }}$ estrofe), parte II:

Foi no horror desta noite tão funérea

Que eu descobri, maior talvez que Vinci,

Com a força visualística do lince,

A falta de unidade da matéria!

(ANJOS, 2002, p.26)

Verificar-se melhor essa inquietação febril do poeta, por quase não conseguir expressar a efervescência da inspiração, no poema "O Meu Nirvana”. Novamente, Augusto do Anjos retoma fundamentos orientais e acerca-se da consciência sobre a incorporeidade das idéias, enquanto almeja a verdade absoluta da alma por intermédio de itinerários (Dharma) pelos quais se ensinam e praticam as crenças de Buda. Escolhe-se o "Caminho do Meio", a renúncia aos prazeres alimentados pelos sentidos e à espiritualização exageradamente ascética. Atingir o Nirvana 6 , como consta na estrofe inicial de "O Meu Nirvana", em decorrência desses ensinamentos, denso processo mental venerado intensamente pelos seguidores do Budismo. Justifica-se, na segunda estrofe, com a proposição inicial "tudo é dor", a causa da celebração budista, predominante na filosofia de Schopenhauer ${ }^{7}$. Eis o trecho desse poema no qual o poeta adere, num misto de comoção e arte, a sua tentativa:

\footnotetext{
No alheamento da obscura forma humana,

De que, pensando, me desencarcero,

Foi que eu, num grito de emoção, sincero,

Encontrei, afinal, o meu Nirvana.

Nessa manumissão schopenhaueriana,

Onde a Vida do humano aspecto fero

Se desarraiga, eu, feito força, impero

Na imanência da Idéia Soberana!

(ANJOS, 2002, p. 111)
}

A alegórica mortificação, proporcionada pela poética de Augusto, realça toda a precariedade do ser, mas reforça ao mesmo tempo sua condição como ente universal. Para os

\footnotetext{
${ }^{4}$ Lucrécio (Roma 99/98 ? - 55 a.C.) "De Rerum Natura”.

${ }^{5}$ A rota mística possui oito regras: 1-Opinião correta; 2-Fixar pensamentos positivos; 3- Palavra justa; 4- Ações feitas com boas virtudes; 5- Estar em paz com os semelhantes; 6- Preservar a mente sã por cultivo de simpatia, comiseração e igualdade; 7- Considerar a não-permanência, a doença e a temporariedade física e mental; 8Concentração, mantida afastando-se do mundo e dos vícios e alcançar a meditação integral como eterna reflexão.

${ }^{6}$ Nirvana: nas religiões hindus e búdicas, o nirvana é o estado supremo da não-existência, não-encarnação e de absorção do ser no brahman - deidade protetora no Budismo. É o estado de pureza absoluta da alma que permite a ela se integrar no todo; (FREDERIC, Louis. Dictionaire de la Civilization Indienne).

${ }^{7}$ O filósofo Arthur Schopenhauer (1788 - 1860) buscou as causas da loucura; acreditava que viver levaria, afinal, à auto-destruição pela rivalidade, luta e destruição, as características, por conseguinte, essenciais da vida.
} 
seguidores de Buda, devem os homens buscar a abnegação das emoções frente às instabilidades da vida. E a solidão distingue-se como um estado de autoconhecimento, objetiva estimular a propagação espiritual de pensamentos. Então o desprezo pelo corpo humano não adquire vigor por meramente sinalizar um gesto de sofrimento, pelo contrário, subentende-se a isso o êxtase de libertação perante a contigüidade orgânica da integridade vital, visto que para a religião budista o indivíduo é fisicamente mero objeto, sempre propenso a reações e sensações arbitrárias. O caminho da iluminação, logo, abala a compleição natural do sujeito sob essa forma de catarse. A autoflagelação, em conformidade com os budistas indianos, é a alternativa para encontrar, portanto, esse percurso clarificado nas asceses de rituais religiosos.

Certamente, o poeta do $E u$ questiona a ausência de clareza quanto ao princípio da vida. $\mathrm{O}$ ímpeto do $E u$ remete-se às origens obscuras para altercar a razão da mortalidade ou o motivo da existência. O "Monólogo de uma Sombra", absorção lírica sob duas vozes, introduz o rigor dessa peripécia teleológica, concedendo voz à própria sombra, uma voz dotada de inteligibilidade e dispondo-se a nossa compreensão. Nesse espectro mítico da sombra pode-se registrar que essencialmente é o mito, por análise do filólogo Max Müller apud Ernst Cassirer $^{8}$, "algo condicionado e mediado pela atividade da linguagem" e, mais adiante, comenta acerca da mitologia como a "obscura sombra que a linguagem projeta sobre o pensamento, e que não desaparecerá enquanto a linguagem e o pensamento não se superpuserem completamente: o que nunca será o caso". Transpondo-se ao primitivismo mitológico, através da sombra que o homem carrega sempre consigo, essa mancha metafísica simboliza a possibilidade de remontar, lingüisticamente, ao passado longínquo do gênero humano. De início, a sombra, em papel discursivo, tenta reconhecer a ascendência biológica advinda das entranhas marítimas ao citar o pólipo, celenterado aquático, mas que, na sublimação promovida pela metáfora, migra minimamente para a forma de larva. Passemos ao resultado poético:

\footnotetext{
"Sou uma sombra! Venho de outras eras Do cosmopolitismo dos moneras... Pólipo de recônditas reentrâncias, Larva de caos telúrico, procedo Da escuridão do cósmico segredo, Da substância de todas as substâncias! (ANJOS, 2002, p. 9)
}

\footnotetext{
${ }^{8}$ CASSIRER, Ernst. Linguagem e Mito (p.18-19).
} 
Em função da singularidade dos elementos que nos constitui, Leibniz, filósofo metafísico ligado às ciências ocultas e à alquimia, teoriza em 1714 sobre as mônadas ${ }^{9}$ "Monadologia"-, unidades de força interna presente em cada indivíduo, pelas quais expressam o universo ao redor dentro de si mesmas, e substancialmente definem o ser como indivisível, e uno por haver distinções similares dentre os seres. É como se a mônada abarcasse todas as coisas existentes e que cada parte desse todo também englobasse tudo, infinitamente. Representamos "um espelho vivo e perpétuo do universo". O corpo, compreendido como resultado da criação divina e vinculado ao pleno pela matéria, sofre individualização com a alma que the representa, sendo a alma outra maneira de representação do cosmos. Do "Monólogo da Sombra", a estrofe sucedida da inicial traz esse entendimento nas palavras densas de Augusto dos Anjos, destinadas a confluírem para a abstração do pensar filosófico:

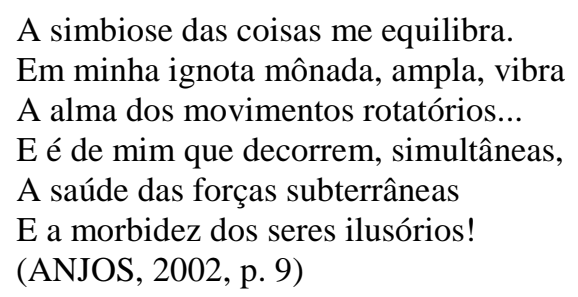

Nesse poema de longa extensão, a sombra, "larva" que nunca terá a corporalidade humana, acrescida de linguagem, segue com seu canto grave, falando sobre o circuito da matéria, a vivência não raro predestinada à reencarnação, cultuada no Bramanismo, a evolução biológica e racional do homem, ainda que carregada de obscuridade, morbidez e de referências mitológicas. Vamos ao final do discurso da sombra:

Continua o martírio das criaturas:

— O homicídio nas vielas mais escuras,

- O ferido que a hostil gleba atra escarva,

— O último solilóquio dos suicidas

E eu sinto a dor de todas essas vidas

Em minha vida anônima de larva!"

(ANJOS, 2002, p. 14)

A subseqüente voz, que confirma o antecedente e elevado solilóquio, atesta o fenômeno sombrio que profere os versos, remetendo a valores de brandura e tristeza, concedidas à natureza, o lirismo que verte a purificação do físico na sua subjacente destituição orgânica. Finalizando o monólogo, as últimas estrofes do poema:

Disse isto a Sombra. E, ouvindo estes vocábulos,

\footnotetext{
${ }^{9}$ Gottfried Wilhelm Leibniz (1646-1716), sobre as mônadas: "Mas hoje, desde que se apercebeu, por pesquisas exatas feitas em plantas, insetos e animais, que os corpos orgânicos da natureza nunca são produtos dum caos ou duma putrefação, mas sempre de sementes, em que havia, sem dúvida, alguma pré-formação, pensou-se que o corpo orgânico não só estaria nelas, já antes da concepção, como também já estaria uma alma neste corpo -numa palavra: o próprio animal de outra espécie. Verifica-se, até, algo semelhante fora da geração, como quando os vermes se convertem em moscas e as lagartas em borboletas."
} 
Da luz da lua aos pálidos venábulos,

$\mathrm{Na}$ ânsia de um nervosíssimo entusiasmo,

Julgava ouvir monótonas corujas,

Executando, entre caveiras sujas,

A orquestra arrepiadora do sarcasmo!

Era a elegia panteísta do Universo,

Na podridão do sangue humano imerso,

Prostituído talvez, em suas bases...

Era a canção da Natureza exausta,

Chorando e rindo na ironia infausta

Da incoerência infernal daquelas frases.

E o turbilhão de tais fonemas acres

Trovejando grandíloquos massacres,

Há de ferir-me as auditivas portas,

Até que minha efêmera cabeça

Reverta à quietação da treva espessa

E à palidez das fotosferas mortas!

(ANJOS, 2002, p. 14-15)

$\mathrm{O} E u$, de alguma forma, simboliza um futuro de morte e violência. A Literatura Brasileira do século XX é marcada não raro pelo contexto irascível das guerras; grande parte de literatos ou artistas segue ao encontro da reação que sentem diante de ataques e massacres bélicos, respondendo à crueldade do mundo com provocações, cumprindo os revides na literatura que, por assim dizer, acarreta na interpretação de convulsões coletivas de um momento agora envolto à memória histórica. Tal arte também viceja na perplexidade que é provocada em nós devido a uma ação praticada contra a política intervencionista norteamericana, realizada na última década de setenta: em protesto contra a Guerra do Vietnã um monge budista imola-se diante dos olhos da história. No corpo, o apoio para a reivindicação e, ao mesmo tempo, alvo de conotação artística pelo impacto da imagem, uma intenção bastante aprofundada pelas convicções do Budismo. E o artista ou o escritor, perseguido pela morte e por aquilo que reflete, estando sujeito aos acontecimentos que o rodeia, reforça sua inspiração recoberta de feridas, as suas e as dos outros. Através do horror da Segunda Guerra Mundial, ganhamos a sensibilidade lírica de Carlos Drummond de Andrade sob tom de desabafo em "Nosso Tempo", nos seguintes versos: “[...] Mas eu não sou as coisas e me revolto. /Tenho palavras em mim buscando canal, / São roucas e duras, irritadas, enérgicas, /comprimidas há tanto tempo, /Perderam o sentido, apenas querem explodir[...]" (ANDRADE, 2000, p. 30) E acrescenta-se a isso o enigma da vida, a nossa pergunta: de qual epifania vem a aleluia de viver? Lembremos a Clarice Lispector: "Venho do longe - de uma pesada ancestralidade. Eu que venho da dor de viver" (LISPECTOR, 1998, p. 15-16).

Augusto dos Anjos distinguiu a fermentação de ideologias e de novos costumes que estavam irrompendo enquanto desfrutava de sua breve efemeridade. A ele se apropriara criar 
a arquitetura da imaginação que lhe inspiraram os versos de sua obra. O poeta faz libação com o sangue dos homens e repugna o organismo humano, para depois utilizá-lo como dádiva fúnebre ao mistério do princípio de todas as coisas e da própria humanidade. O poeta Augusto, acima de tudo, é autor de uma literatura enigmática, quase incompreendida, e perpetua-se como um homem incomum, sombreado atrás de idéias e pensamentos - que permanecem vivificados na sua linguagem.

\section{Referências}

ANDRADE, Carlos Drummond de. A Rosa do Povo. Rio de Janeiro: Record, 2000.

ANJOS, Augusto dos. Eu e Outras Poesias. Porto Alegre: L\&PM, 2002.

FILHO, Milton Benedicto Barbosa; STOCKER, Maria Luiza Santiago. História Moderna e Contemporânea. 4.ed. São Paulo: Scipione, 1944.

GRANDES PERSONANGENS da História Universal. São Paulo: Abril Cultural, v. 5, 1972.

LISPECTOR, Clarice. Água Viva. Rio de Janeiro: Rocco, 1998.

LYNTON, Norbert. O Mundo da Arte Moderna. Encliclopédia Britânica do Brasil, 1979.

MELO, A. L. Nobre. Augusto dos Anjos e as Origens de sua Arte Poética. Rio de Janeiro: José Olympio, 1942.

THOMAS, Henri; THOMAS, Dana Lee. Vida de Grandes Filósofos. 5. ed. Rio de Janeiro: Globo, 1950.

VIDAL, Ademar. O Outro eu de Augusto dos Anjos. Rio de Janeiro: José Olympio, 1967. 